\title{
Sudden infant death syndrome, population mixing and oil-related development in western Norway
}

\author{
Graham Bentham ${ }^{1}$ and Asbjørn Aase ${ }^{2}$ \\ ${ }^{I}$ Centre for Environmental Risk, School of Environmental Sciences, University of East Anglia, Norwich NR4 7TJ, England \\ ${ }^{2}$ Department of Geography, Norwegian University of Science and Technology, N-7034 Trondheim, Norway
}

\begin{abstract}
A number of features of sudden infant death syndrome (SIDS) point to an aetiological role for apparently minor infections. The spread of infections is influenced by the rate of contact between infectious cases and susceptibles in the population. This is likely to differ geographically depending on patterns of social contacts, with epidemics being particularly likely where an influx of migrants leads to high rates of mixing of populations lacking herd immunity. It has been shown that geographical variations in SIDS deaths in England and Wales are strongly associated with rates of long distance in-migration into districts. The large influx of population into parts of western Norway as a result of oil-related development provides an opportunity to examine this issue further. The most intensive development has been in the Stavanger area in the county of Rogaland. Published migration statistics show that there was a rapid build-up of long distance migration into this area reaching a peak in the late 1970s. Further north, the Bergen area in the county of Hordaland was little affected by oil-related activities in the 1970s. However, the more recent development of oil provinces further north has led to more activity in the Bergen area and an increase in in-migration from the mid 1980s onwards. Annual data from 1969 onwards on SIDS deaths in Rogaland and Hordaland counties and for Norway were used to assess whether trends in SIDS mortality and migration showed any associations. Before the main population influx Rogaland had a SIDS rate that was below the Norwegian average. However, since the mid 1970s SIDS rates have been significantly in excess of the national average. In Hordaland SIDS rates were low throughout the 1970s but increased substantially to be significantly in excess of the Norwegian average in the late 1980s. In both areas population influxes resulting from oil-related development were therefore followed by a significant increase in mortality rates from SIDS. There is no evidence that these trends can be accounted for by changing patterns of known risk factors for SIDS in these areas nor of artefacts in the registration of SIDS cases. The results of this study therefore support the British evidence that population mixing may be a significant factor in the aetiology of SIDS.
\end{abstract}

\section{INTRODUCTION}

Several features of the epidemiology of sudden infant death syndrome (SIDS) point to an aetiological role for infections. As is the case for common respiratory infections SIDS shows marked seasonality with a substantial rise in risk during the winter months (1). More direct evidence comes from studies showing that compared to control groups more victims of SIDS were reported by their parents to have displayed symptoms of apparently minor infections in the days preceding death and were more likely to have been seen by a general practitioner (2) and have been admitted to hospital (3). Signs of infection by common viruses have also been found in post-mortem investigations of cases of SIDS and it has been suggested that such infections may precipitate an abnormal immune response capable of causing death (4).
As well as varying over time it is also likely that exposure to common infections, and any SIDS risk associated with such exposure, will differ geographically. The spread of infections is regulated by the rate of contact between infectious cases and susceptibles in the population (5). This rate of contact is likely to differ from one area to another depending on the pattern of social contacts of the population. In stable communities with low levels of contact with other populations high levels of herd immunity are likely to develop. This may not be the case in more mobile communities where there are substantial numbers of migrants from other places. When migrants move over long distances they are unlikely to have had much previous contact with the local population and they might bring with them infections for which this population lacked immunity. Also, by increasing the pool of susceptibles, migrants can encourage the spread of an infection that 
was endemic in the host population. Kinlen et al. (6) have proposed that such processes could be of relevance in the aetiology of childhood leukaemia which, they argue, may be a rare response to an infection (or infections) the transmission of which is facilitated by population mixing. Empirical evidence in favour of this hypothesis comes from the demonstration of significant excesses of childhood leukaemia in some new towns (6), in areas experiencing an increase in commuting (7), in rural areas which saw an influx of military personnel during the 1950s (8) and in areas of Scotland where there was an influx of population as a result of oil-related development (9). The possible role of population mixing in sudden infant death syndrome was examined in a study of the geographical variations in SIDS in England and Wales (10). This showed a highly significant positive association between SIDS rates in different areas and their levels of long-distance in-migration. After adjusting for confounding factors SIDS rates were $66 \%$ higher in areas in the upper than in the lower quartile of in-migration. These findings were judged to support the hypothesis that population mixing, by its influence on exposure to infections, may be a significant factor in the aetiology of sudden infant death syndrome.

In this previous investigation of the association between population mixing and SIDS the approach used was cross-sectional. One way of examining the issue further would be to undertake a study of a community where there had been a marked change over time in the amount of population mixing as a result of an influx of long-distance in-migrants. The large influx of population into parts of western Norway as a result of oil-related development provides an opportunity to examine this issue further. The most intensive development has been in the Stavanger area in the county of Rogaland which was the part of Norway closest to the earliest large fields to be developed. Further north, the county of Hordaland which includes the city of Bergen was less affected by oil-related activities in the 1970s. However, the more recent development of oil provinces further north has led to more activity in the Bergen area. A useful indicator of the magnitude and timing of the changes in population mixing that has accompanied the oil-related development is provided by published figures (11) on annual rates of inmigration from abroad into the two counties of Rogaland and Hordaland. Figure 1 shows that in Rogaland during the 1970s there was a rapid build-up of long distance in-migration reaching a peak in 1977 and remaining high thereafter. In Hordaland, except for a small rise in 1976 and 1977 rates of foreign inmigration remained relatively low until the mid-1980s, following which there has a been a substantial increase. If population mixing does increase the risk of sudden infant death in the way that is hypothesised the expectation would be that SIDS rates in Rogaland would have risen from the mid-1970s whereas any increase in Hordaland would not be expected until the late 1980s.

\section{METHOD}

Annual data from 1969 onwards to 1989 on SIDS deaths in Rogaland and Hordaland counties and for Norway as a whole were taken from the mortality register of Statistics Norway, through a database designed for geographical analysis in the Department of Geography in Trondheim. Data for later years were not available from this source. The annual number of live-births for these areas were taken from published sources (11) and the annual numbers of SIDS deaths per thousand live-births were calculated. The expected annual number of SIDS deaths in each county were calculated by applying the rates for Norway to the local number of live-births. For the two counties it was then possible to examine trends over time in the difference between the observed and expected numbers of SIDS deaths. The ratios of observed to expected SIDS deaths in each county were calculated and plotted to facilitate comparison of whether the timing of any changes in SIDS risk matched those in in-migration rates. Particularly in the early years when the number of SIDS cases tended to be low there were large year to year fluctuations in the observed to expected ratio. It was therefore decided to aggregate the data into longer time periods to reduce the problem of random variations. Since the study covered 21 years it was convenient to aggregate the observed and expected numbers of SIDS deaths into 3-year periods. The ratios of observed to expected deaths and their 95\% confidence intervals based on the Poisson distribution were calculated.

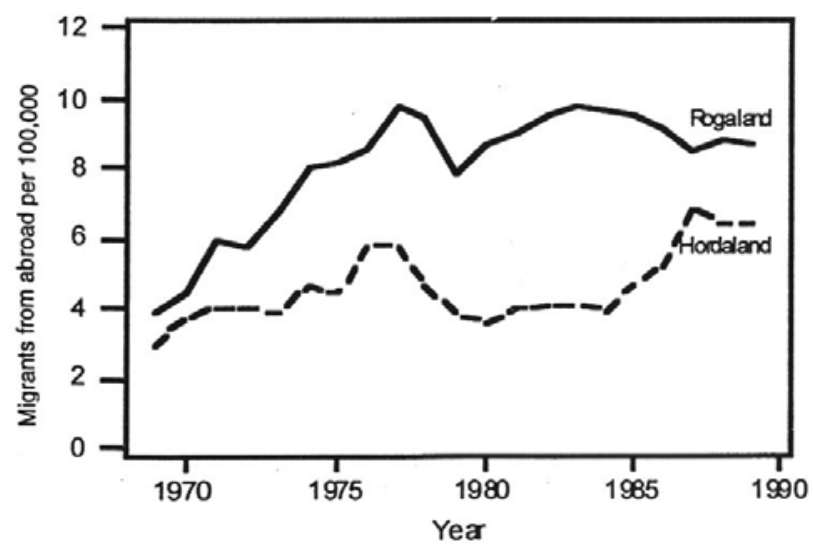

Figure 1. Migrants from abroad per thousand population in Rogaland and Hordaland, 1969-89.

One problem with the analysis is that the apparent changes over time in the incidence of SIDS could be affected by changes in diagnostic practice. Particularly 
in the early part of the study period it is likely that deaths that would previously have been recorded as other causes of infant mortality were increasingly coded as being from sudden infant death syndrome and this would produce an artefactual increase over time in SIDS rates. This is one of the reasons for avoiding reliance on simple rates of SIDS deaths per thousand live-births and using instead the ratio of observed to expected deaths. This adjusts for any factors such as diagnostic changes that might lead to a general change in the recorded incidence of SIDS. However, there remains the problem that the timing or magnitude of diagnostic shifts in Rogaland and Hordaland might differ from the national picture. As well as examining SIDS deaths we therefore also analysed postneonatal deaths from any cause which clearly cannot be affected by diagnostic confusion.

\section{RESULTS}

Figure 2 shows that in the early years of the study period the number of SIDS deaths in Rogaland were lower than expected from national rates. There were fluctuations from year to year, which is not surprising given the low number of deaths, but the generally low SIDS risk is clear with observed numbers being lower than expected in 5 out of the 6 years up to and including 1974. However, from 1975 onwards there was a marked change to an above average risk of sudden infant death which persisted until the end of the period studied. As before there were annual fluctuations but the shift to above average risk is clearly apparent with observed numbers being greater than expected in 11 out of 15 years. This impression of a marked increase in SIDS risk in Rogaland from the mid 1970s onwards is confirmed by the aggregation of data into three-year time periods in Table 1. In both of the first two periods there were fewer than expected numbers of SIDS deaths. Since then there have been excesses of SIDS deaths in all of the five periods studied, of which four have been significant at the 0.05 level.

In the early part of the period studied Hordaland also showed a lower than expected number of SIDS deaths (Figure 3). However, unlike Rogaland this below average risk persisted for much longer with the observed numbers of SIDS deaths exceeding those expected in only 3 of the 17 years up to and including 1985. Since then there are signs of an increase. This evidence of a generally low SIDS risk over most of the study period followed by a sharp deterioration to significantly high rates in the late 1980s is confirmed by the analysis by time-periods in Table 2 .

In both Rogaland (Table 3) and Hordaland (Table 4) the divergence between observed and expected numbers of postneonatal deaths (from all causes) tends to be smaller than for SIDS. Nevertheless, there is considerable consistency in the broad pattern and of changes over time. In Rogaland, as with SIDS, there was a marked increase in mortality rates relative to the

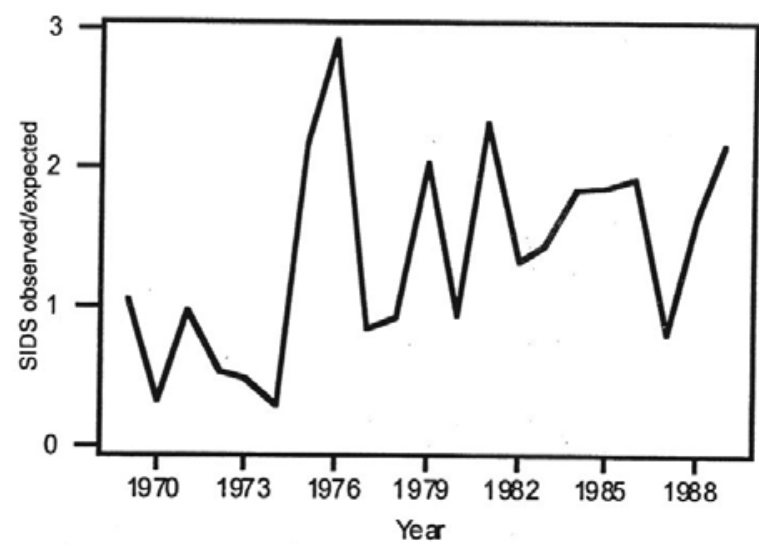

Figure 2. Ratio of observed to expected SIDS deaths in Rogaland 1969-89.

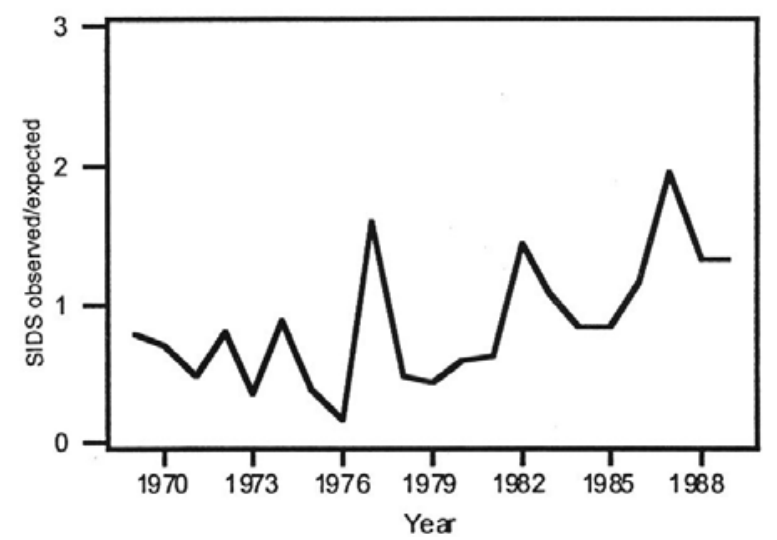

Figure 3. Ratio of observed to expected SIDS deaths in Hordaland 1969-89.

Table 1. Ratio of observed to expected SIDS deaths in Rogaland by time period.

\begin{tabular}{lcccr}
\hline & \multicolumn{4}{c}{ SIDS deaths } \\
\cline { 2 - 5 } Time period & Observed & Expected & O/E & O/E 95\% c.i. \\
\hline $1969-71$ & 7 & 9.0 & 0.78 & $0.31-1.61$ \\
$1972-74$ & 5 & 11.0 & 0.45 & $0.15-1.05$ \\
$1975-77$ & 26 & 13.3 & 1.95 & $1.27-2.86$ \\
$1978-80$ & 28 & 20.7 & 1.35 & $0.90-1.95$ \\
$1981-83$ & 35 & 21.3 & 1.64 & $1.14-2.28$ \\
$1984-86$ & 57 & 30.3 & 1.88 & $1.42-2.44$ \\
$1987-89$ & 55 & 34.1 & 1.61 & $1.21-2.10$ \\
\hline
\end{tabular}

Table 2. Ratio of observed to expected SIDS deaths in Hordaland by time period.

\begin{tabular}{lcccr}
\hline & \multicolumn{4}{c}{ SIDS deaths } \\
\cline { 2 - 5 } Time period & Observed & Expected & O/E & O/E 95\% c.i. \\
\hline $1969-71$ & 8 & 11.9 & 0.67 & $0.29-1.32$ \\
$1972-74$ & 10 & 15.0 & 0.67 & $0.32-1.23$ \\
$1975-77$ & 12 & 16.4 & 0.73 & $0.38-1.27$ \\
$1978-80$ & 12 & 23.3 & 0.52 & $0.27-0.91$ \\
$1981-83$ & 26 & 24.0 & 1.08 & $0.71-2.24$ \\
$1984-86$ & 32 & 33.5 & 0.96 & $0.66-1.36$ \\
$1987-89$ & 58 & 38.6 & 1.50 & $1.14-1.94$ \\
\hline
\end{tabular}


Table 3. Ratio of observed to expected post-neonatal deaths from all causes in Rogaland by time period.

\begin{tabular}{lcccc}
\hline & \multicolumn{4}{c}{ SIDS deaths } \\
\cline { 2 - 5 } Time period & Observed & Expected & O/E & O/E 95\% c.i. \\
\hline $1969-71$ & 53 & 51.2 & 1.04 & $0.78-1.36$ \\
$1972-74$ & 41 & 45.6 & 0.90 & $0.64-1.22$ \\
$1975-77$ & 50 & 43.7 & 1.14 & $0.84-1.50$ \\
$1978-80$ & 61 & 46.4 & 1.31 & $1.00-1.68$ \\
$1981-83$ & 66 & 46.6 & 1.42 & $1.10-1.81$ \\
$1984-86$ & 81 & 55.3 & 1.46 & $1.16-1.81$ \\
$1987-89$ & 77 & 61.9 & 1.24 & $0.98-1.55$ \\
\hline
\end{tabular}

Table 4. Ratio of observed to expected post-neonatal deaths from all causes in Hordaland by time period.

\begin{tabular}{lcccc}
\hline & \multicolumn{4}{c}{ SIDS deaths } \\
\cline { 2 - 5 } Time period & Observed & Expected & O/E & O/E 95\% c.i. \\
\hline $1969-71$ & 64 & 67.8 & 0.94 & $0.72-1.20$ \\
$1972-74$ & 54 & 62.3 & 0.87 & $0.65-1.14$ \\
$1975-77$ & 43 & 54.2 & 0.79 & $0.57-1.07$ \\
$1978-80$ & 37 & 52.5 & 0.70 & $0.49-0.97$ \\
$1981-83$ & 49 & 52.5 & 0.93 & $0.69-1.23$ \\
$1984-86$ & 56 & 61.1 & 0.92 & $0.69-1.20$ \\
$1987-89$ & 87 & 69.8 & 1.25 & $1.01-1.54$ \\
\hline
\end{tabular}

national average from the mid 1970s onwards. In Hordaland postneonatal mortality rates remained below the national average until the late 1980s when, as for SIDS, there was a sharp increase.

\section{DISCUSSION}

In the early 1970 s, before the major influx of population associated with oil-related development, SIDS risk in Rogaland was below the average for Norway as a whole. Following this influx there was a large and persistent increase in SIDS incidence such that risk has been above the Norwegian average since the mid1970 s, significantly so (at the 0.05 level) in four out of five periods. This means that Rogaland saw a remarkable change from substantially below to substantially above average SIDS risk with the change following shortly after the population influx. During the 1970s there was little change in the relative risk of SIDS in the neighbouring county of Hordaland, which was little affected by oil-related development or inmigration. Factors such as unusual patterns of weather conditions which would have affected the whole of western Norway cannot have caused the rise in Rogaland since they would have also produced a corresponding increase in Hordaland, and none was observed. Instead, some more localised aetiological factor had begun to operate strongly in Rogaland, but not in nearby Hordaland. The possibility that this was an increase in population mixing associated with oildevelopment is further supported by the fact that when Hordaland did experience an influx of population in the late $1980 \mathrm{~s}$, as the balance of oil activity moved northwards, there was a sharp rise in SIDS incidence.

One possibility is that the observed increases in SIDS incidence in Rogaland and Hordaland was the result of changes in diagnostic practices with some deaths that were previously attributed to another cause being classified as SIDS cases. If this was the case the increase in SIDS deaths would have been matched by a corresponding reduction in deaths from other causes, with overall death rates remaining constant. The analysis of changes over time in postneonatal mortality from all causes shows that this was not the case. In Rogaland these increased from the mid 1970s onwards, whereas in Hordaland a substantial increase did not take place until the late 1980s. This suggests that the observed changes in the relative risk of SIDS in the two counties is unlikely to have been the result of changing diagnostic practice.

Another explanation for the observed changes and their association with changes in population mixing might be confounding by some known aetiological factor for SIDS. For example, there is overwhelming evidence that the prone sleeping position increases risk and that the numbers of SIDS deaths in Norway (12) and several other countries (13-15) have fallen substantially following campaigns to change sleeping position. However, the period covered by the present study was before widespread acceptance of this risk or actions to avoid it and there is no evidence that there were marked changes towards the prone sleeping position in Rogaland in the mid 1970s and Hordaland in the late 1980s. SIDS risk is also known to be related to adverse socioeconomic circumstances (3) but income levels in Rogaland and Hordaland (11) have tended to increase relative to the Norwegian average suggesting that social conditions have improved, not deteriorated. Similarly, illegitimacy is associated with high SIDS risk (3) but illegitimacy rates in Rogaland and Hordaland have remained below the Norwegian average throughout the period studied. It is also known that maternal smoking (11) increases the risk of SIDS but rates of cigarette smoking by women in Rogaland and Hordaland were below the national average at the time when the SIDS death rates went above the national rates (16). There is therefore no evidence that the observed changes in SIDS risk can be accounted for by known aetiological factors, although confounding by other unsuspected risk factors can never be excluded.

Therefore, we conclude that in both areas population influxes resulting from oil-related development were followed by a significant increase in mortality rates from SIDS. Since there is no evidence that these trends can be accounted for by changing patterns of known risk factors for SIDS in these areas or of artefacts in the registration of SIDS cases an alterna- 
tive explanation is required. The consistency of the findings of the present study with the earlier crosssectional British study (10) support the hypothesis that population mixing may be a significant factor in the aetiology of SIDS. It is also consistent with evidence of associations between population mixing and the incidence of childhood leukaemia (6-9). Our study design does not provide direct evidence on the mechanisms by which population mixing might affect the risk of SIDS. However, the association that has been observed is consistent with population mixing exerting an influence on exposure to common infections which may be involved in some sudden infant deaths. Recently it has been shown (17) that infants shown to have abnormally long QT intervals on electrocardiograms are at greatly increased risk of SIDS. It is unlikely that the proportion of infants with prolonged QT intervals would vary geographically and temporally in ways that would directly explain the variations in SIDS risk observed in the present study. A more plausible explanation is suggested by the authors of the new study who point out that since most infants with prolonged QT intervals did not die of SIDS some other factors must interact with the prolonged QT intervals in the postnatal period to precipitate the lethal event. Given the strong evidence (5) of an aetiological role for infections in SIDS these are clearly one amongst a number of possibilities.

\section{REFERENCES}

1. Osmond C, Murphy M. Seasonality in the sudden infant death syndrome. Paediatr Perinat Epidemiol 1988; 2: $337-45$.

2. Gilbert RE, Fleming PJ, Azaz Y, Rudd PT. Signs of illness preceding sudden unexpected deaths in infants. BMJ 1990; 300: 1237-9.

3. Golding G, Limerick S, Macfarlane A. Sudden infant death: puzzles, patterns and problems. Shepton Mallet: Open Books, 1985.

4. Howat WJ, Moore IE, Judd M, Roche WR. Pulmonary immunopathology of sudden infant death syndrome. Lancet 1994; 343: 1390-2.

5. Fox JP, Elveback L, Scott W, Gatewood L, Ackerman E. Herd immunity: basic concept and relevance to public health immunization practices. Am J Epidemiol 1971; 94: 179-89.

6. Kinlen LJ, Clarke K, Hudson C. Evidence from population mixing in British new towns 1946-85 of an infective basis for childhood leukaemia. Lancet 1990; 336: 577-82.

7. Kinlen LJ, Hudson CM, Stiller CA. Contacts between adults as evidence for an infective origin of childhood leukaemia: an explanation for the excess near nuclear establishments in West Berkshire? Br J Cancer 1991; 64: 549-54.

8. Kinlen LJ, Hudson C. Childhood leukaemia and poliomyelitis in relation to military encampments in England and Wales in the period of national military service, 1950-63. BMJ 1991; 303: 1357-62.

9. Kinlen LJ, O'Brien F, Clarke K, Balkwill A, Matthews F. Rural population mixing and childhood leukaemia: effects of the North Sea oil industry in Scotland, including the area near Dounreay nuclear site. BMJ 1993; 306: $743-8$.

10. Bentham G. Population mixing and sudden infant death syndrome in England and Wales. Int $J$ Epidemiol 1994; 23: 540-4.

11. Statistics Norway. Statistical Yearbook. Oslo: Statistics Norway, various dates.

12. Daltveit AK, Øyen N, Skjaerven R, Irgens LM. The epidemic of SIDS in Norway: changing effects of risk factors. Arch Dis Child 1997; 77: 23-7.

13. Department of Health. Report of the Chief Medical Officer's Expert Group on the Sleeping Position of Infants and Cot Death. London: HMSO, 1993.

14. de Jonge GA, Burgmeijr RF, Engelberts AC, Hoogenboezem J, Kostense PJ, Sprij AJ. Sleeping position for infants and cot death in the Netherlands 1985-91. Arch Dis Child 1993; 69: 660-3.

15. Mitchell EA, Brunt JM, Everard C. Reduction in mortality from sudden infant death syndrome in New Zealand: 1986-92. Arch Dis Child 1994; 70: 291-4.

16. Smoking survey data from Statens tobakkskaderåd/Statistisk sentralbyrå, obtained through Norsk samfunnsvitenskapelig datatjeneste.

17. Schwartz PJ, Stramba-Badiale M, Segantini A, et al. Prolongation of the QT interval and the sudden infant death syndrome. N Engl J Med 1998; 338: 1709-14. 